\title{
Biopolitical Marketing and Technologies of Enclosure
}

\author{
Detlev Zwick and Janice Denegri-Knott
}

\section{Introduction}

Recently, there has been a lot of talk about consumer empowerment through new information and communication technologies. Corporate captains of marketing, Wired Magazine’s neo-libertarian technoutopians, marketing consultants of the digital economy and many marketing academics agree that we all have more choices, more information, more entertainment, more transparency, and lower prices thanks to Amazon, Facebook, Youtube, and all the rest. We are liberated from the burdens of material ownership, free to access digital objects and services in ways that satisfy our needs in highly targeted and efficient ways. The empowerment through technology chorus is so loud and cohesive that we generally take the message for granted. And in some limited respect, consumers may feel empowered when shopping on Amazon.com or in the malls with their iPhones on hand. But let us be very clear about the idea of empowerment that is promoted by the cheerleaders of what Jodi Dean (2005) calls communicative capitalism. Real empowerment, so much should be clear, will never be "granted" to consumers by those in economic (and thus political) power. In the final analysis - and putting aside for a moment the fact that even empowered consumers are still interpellated first and foremost as subjects of consumption - the ideal of the empowered consumer (rational, enlightened, informed, restrained, un-manipulable) is completely antithetical to the needs of capital and the marketing regime within consumer capitalism. Therefore, any call for actual consumer empowerment would automatically be a radical demand and an insurgent claim aimed at undermining and replacing capital's power to dominate the consumer totally. In the end, it is important to recognize that any technology employed by marketing today becomes a technology of enclosure (even if never completely successful), which permits empowerment only in a version sanction by capital. That is why marketing (and capital more generally [see Lazzarato, 2004]) today is biopolitical. It wants to govern life completely while appearing to not govern at all.

In this chapter we argue that new technologies in contemporary marketing management are best thought of as technologies of enclosure. On the one hand, marketing encloses the subject as individualized and individuated consumer. On the other, marketing aims to enclose (ie., capture, make proprietary, 
appropriate) what is common or collectively produced or cherished by individuals as inalienable expressions of personal identity and agency. At the same time that marketing encloses, it operates ideologically, although not in the classical Marxist sense of creating a false consciousness. Rather, the challenge for marketers is to enclose and capture the subject and the common while appearing not to do any of these things. By accepting as non-ideological terms such as choice, identity, fulfillment, empowerment, enrichment, collaboration, creativity and so on, marketers and consumers alike choose to believe, just as anyone sensible would believe, that new techniques and technologies of enclosure are really just good marketing practice aimed at value creation and delivery, not customer domination and exploitation.

We should remember that an atmosphere of distrust has accompanied the development of marketing from the beginning and marketers have long been suspected of being professional manipulators, devising salacious techniques and technologies with which to incite, manipulate and exploit consumer desire and anxiety. As Packard put it fifty years ago, “[T]hese depth manipulators are in their operations beneath the surface of conscious life, starting to acquire a power of persuasion that is becoming a matter of justifiable public scrutiny and concern” (1957, pp. 9-10). More recent popular indictments of marketing include Adam Curtis's documentaries on The Century of the Self, Naomi Klein's No Logo (2000), and the BBC series The Men Who Makes Us Spend (presented by Jacques Peretti).

Criticism of marketers is compounded by widespread consumer cynicism regarding the genuineness of marketing messages (see Gabriel and Lang, 1995). Interestingly, the emerging generation of online marketers- typically referred to as digital or social media marketers - see marketing's crisis of legitimacy directly tied to what it considers the corporate, top-down marketing methods devised in the 1970s and 1980s and designed to discipline and control consumers. For a new generation of tech-savvy marketers, imbued with a solid dose of techno-libertarian ideals of independence and a frontier mentality that rejects top-down authority and bureaucracy in favor of self-organizing systems, radical autonomy and freely collaborative networks, a dramatic shift in mindset was needed in the age of participatory media and Big Data. In a radical turn propagated, for example, by prominent social media marketing experts like Solis (2010) and Stratten (2010), marketing has to be 'un'-done. The term 'un-marketing' rises to prominence in the consulting literature and offers a reframing of marketing that rejects corporate-controlled top-down techniques, and favours horizontal, collaborative, and participatory customer engagement (Kutcher, 2010, Stratten, 2010, 2014). In this context, the idea of online customer communities gains popularity because it provides a fantasy of restructuring marketplace relations according to principles of co-creation, sovereignty, equality, and sharing. More recently, what we call Big Data marketing is framed according to similar registers where data magnetizes consumers and marketers to a shared ethos of the "opt-in" 
economy (Godin, 1999). Big Data marketers - at least in the version propagated by Google’s Hal Varian, for example - pose innocuously enough as personal recommendation and consulting agents for consumers who in return for giving up personal information receive ever more relevant, valuable, and desired information, goods and services (Zuboff, 2015). Who would not like such a deal that appears to be based on liberal ideals of good intentions on all sides and the equal distribution of costs and benefits, even as companies manage communities and customer data not on behalf of consumers but on behalf of corporate profit.

In sum, new marketing technologies - from blogs to communities to surveillance-based collaborative filtering and recommender systems - no matter how invasive, ever-present and insidious, have been framed by technology-driven marketers as democratizing and equalizing forces reshaping the contemporary marketplace in favor of the consumer. Customer and brand communities are happy places of collaboration and collective value creation governed by an ethos of mutual respect, sharing and dispersed control. Big Data Marketing, which aspires to intensifying consumer surveillance and control (Zuboff, 2015), is often presented as part of the contemporary ethos of collaborative 'in-this-togetherness' and collective support structures between companies and consumers. Marketers are asked to employ Big Data to better understand, assist, support and connect with customers; the technology magnetizing both exchange parties to a fantasy of better products, better choices, better experiences, better prices, better service and generally happier lives. To live in a world where companies strain to innovate and please consumers, all we need to do in return is give companies complete access to our personal information. Such a request makes sense to a generation of marketing professionals and consumers that have grown up with Google, Facebook and Amazon tracking its every move.

In the next section we explore critically new marketing technologies such as online customer communities and Big Data, and possession of digital objects as consumer lock in. .We suggest that these technologies are technologies of Biopolitical Marketing. They aspire to enclose all forms of life for profit. We suggest that marketing innovation is now structured according to the imperative of biopolitical marketing: the making, valorizing and enclosing of all forms and expressions of life.

\section{Online Community Marketing}

We should have no illusions about the new marketers of the social media age, what meme hustler Tim O’Reilly (Morozov, 2013) has termed Web 2.0. As these ‘un-marketers' replace the disciplinary technologies of marketing with technologies of communitarian self-governance, two-way communication 
and collaboration, new contradictions emerge characteristic of communicative capitalism. Specifically, even a community of autonomous, creative, collaborative and networked participants must be commercially exploited- this is, after all, still marketing's raison d'être. Social media marketers understand this practical challenge of commodifying communicatively structured social relations that do not want to be commodified. Or, to put it another way, marketers must enclose the space where production of reproduction of the common takes place (Cvijanovic, Vercellone, and Fumagalli, 2010; Hardt and Negri, 2009). The trick is to privatize without disrupting what Dyer-Witheford (2009) calls the circuit of the common, where collectives or associations of people "organise shared, common resources including creativity, machinery and resources into productive ensembles that create more commons which in turn provide the basis for new associations.”

Mastering the paradox of on the one hand enabling, and enabling sharing of, human creativity and cognitive production owned by no one and on the other exploiting the work of the many for the benefit of the few requires the 'correct marketing mind-set.' Internet marketing consultant Tamar Weinberg (2009, pp. 52-53) articulates this tension in unmistakable terms:

Later, your 'ulterior motive' can be communicated (just as long as you continue giving back to the community and its members look up to you as a respected contributor), but it's more important to establish yourself as a reputable member who wants to give back to the community first. Once you do, you can begin to take, as long as the community is receptive and wants to know more about you as a community participant, but you should always keep giving.

There is something revealing about the frantic back and forth between the double exhortation to keep giving and making sure to 'take'. The new technologies of marketing render give-and-take immediate and necessary. Weinberg understands that marketing must take, but that it must do so without appearing to take (by also giving back). There is no cynicism or element of conscious deception at work when new marketers talk about the riches to be found in the common spaces of the wild Web 2.0. Rather, marketers of the digital age really do believe that when the new commons of communicative capitalism produce creative and cognitive value it belongs to them as much as to anyone else. To extract communicative surplus value from the community marketers must adopt a 'commun-ist sensibility' (Zwick and Bradshaw, 2016). As actor-cum-social media consultant Ashton Kutcher puts it (Solis, 2010, p. ix):

The roles are reversing and individuals and brands have the ability to reach and rouse powerful and dedicated communities without ever having to pay for advertising. I'm just part of a bigger movement of empowering the people who care enough to change the world. Social media is socalising causes and purpose and inciting nothing short of a revolution.” 
At the heart of this utopian conception of communal marketing is the idea of a perfect communion with consumers based on a sincere belief that 'we all want the same thing'. From this vantage point, appropriating for corporate profit the affective, communicative and cognitive work of communities is entirely justified, if not required if marketers are to hold up their end of the bargain and deliver all the good things they promise in return for this appropriation.

A neo-libertarian impulse defines the enthusiasm of Kutcher, Solis and others (see e.g. Rubel in Miller, 2008; Downes and Mui, 2000). Consumer community marketing is imagined as the logical extension of the cyber-utopian project in which horizontality, anti-authority, and bottom-up power facilitate entrepreneurialism, value creation, and innovation. Representative of the neo-libertarian narrative is Kevin Kelly’s (2009) enthusiastic announcement of the arrival of a 'global collectivist society’ which, he argued, amounts to a 'New Socialism.' This socialism is 'not class warfare. It is not anti-American; indeed digital socialism may be the newest American innovation.’ The irony is that the revolutionary socialism envisioned by Kelly propagates both self-organising and entrepreneurial commons and successful privatization of the common.

Within the communal ethos of digital socialism, marketing transforms into the enactment of consensual partnership with consumers who are no longer controlled but invited by the corporation as equals in the joint-task of co-creation. Hence, practices that control consumers, or absorb them into centralised, technocratic, and rationalised structures appear crude, abusive, and anachronistic. Instead, under conditions of communicative capitalism, marketing must try to enclose the multitude while maintaining the conditions under which the multitude labors cognitively and creatively (see e.g. Fournier and Lee, 2009; Schau, et al., 2009; Weinberg, 2009). For O’Dwyer, this perspective imagines the web as a "virtual communism"; an "immaterial space that trades in knowledge and culture, at once free from commercial subjugation and conversely capable of exerting influence on the material substrate of capital” (O’Dwyer, 2013, p. 498).

Hence the communism of Web 2.0, as described by Kleiner and Wyrick (2007), is one where companies retain ownership of content, while opening up a method of content creation. The popular narrative of Web 2.0 as a democratising force that brings emancipatory empowerment occludes how, as Stallabrass (2012) informs, peer-to-peer systems had previously allowed users control of the frame as well as the content. Therefore, Web 2.0 is an enclosure of a commons and not the other way around. It is in this context that capital wants to harness this commonist ethos in what are in effect privatised spheres (see also Arvidsson and Peitersen, 2013; Beverungen et al., 2013). 
The tension that arises from marketers' pursuit of new modes of commodification versus the multitude's productive value that depends on remaining untouched by the institutional logic of marketing becomes acutely visible in the context of participatory media. Social media marketers like Solis and Weinberg warn that the productive anarchy of the crowd is a statement against institutions, discipline and commercial enclosure. These authors announce that exciting new online activities such as prosumption, peer collaboration, co-creation and crowd sourcing clearly show that consumers do not need - and likely do not want - marketers in the picture. Enclosure of the commons for the benefit of the firm therefore requires marketing techniques and technologies that recruit consumers into value production in a way that appears voluntary and free. Resolving this contradiction becomes the challenge and, in their search for innovative ways of commodifying the crowd without antagonism, marketers turn towards customer communities.

\section{Big Data Marketing}

The customer community is just one example of a technological innovation that is motivated by, consciously or not, resolving this contradiction of marketing under communicative capitalism. Databasedriven marketing, or what we call here Big Data marketing, represents another such technology. The challenge of studying Big Data marketing from a cultural and critical theory perspective is to move beyond the immediate urge to focus on the technology’s intensification of consumer surveillance and control (e.g. Zuboff, 2015) and instead recognize that Big Data is fundamentally motivated and sustained by its ability to generate and enclose value immanent to consumer life. Thus, while very different in technique and operation, Big Data marketing shares with community marketing that it is a technology of biopolitical marketing.

Business sociologist Shoshana Zuboff (2015) suggests the term surveillance capitalism to describe what she calls the logic of creating, collecting, manipulating and, most importantly, valorizing information. She argues, as indeed others have before (e.g. Arvidsson, 2005; Lury, 2004; Zwick and Denegri-Knott, 2009), that today the goal of many technology companies - in fact, increasingly any company because there is a sense that all companies are becoming technology, or at least information companies - is not to produce products or services based on some identified customer need. Instead, companies aim to build what we could call platforms of co-production where consumers do things they want to do and for that privilege they either have to pay the platform provider a fee or they have to pay in other ways (micro transaction, 
eyeballs/data that can be resold, etc.). If the business model is based on information value, the goal is to capture as much information about the users of the platform as possible and then find ways to repackage and commodify this information for a buyer.

The hope is that the more data can be collected and analyzed the more money can be made. This is one reason why data-monitoring technologies are so wide-spread and continue to spread. Taking Google's chief economist Hal Varian's exposition of Google's business model Zuboff develops the notion of surveillance (or Google) capitalism. Varian characterizes Google’s business vision as founded on four pillars, the first one speaks directly to the idea of Big Data: "More data extraction and analysis.” Varian explains how most of the data today is generated via computer-mediated interactions and how all our interactions with machines are recorded and logged for possible mining and analysis. In addition, there is the data generated by the internet of everything. Finally, governments and other non-commercial bureaucratic agencies and groups collect and store data, which is linked to the internet and can be used for analysis.

Zuboff is correct to point out, as others have before (e.g. Fuchs, 2010, 2012; Juergenson, 2010), that data generation, collection and use is based on asymmetrical power relations. Google owns us and our future a lot more than we own Google and its future (Lanier, 2013). The common response by commentators and analysts such as Zuboff to Google's “More data extraction and analysis” doctrine is to focus on Google's desire for a totally knowable and known world of people, markets, goods, and services and their flows. From this perspective, Big Data becomes a matter of privacy invasion, universal surveillance and neoliberal forms of government. However, from the perspective of biopolitical marketing we recognize that Big Data becomes a technique of capture, appropriation and enclosure. Surveillance capitalism is thus not so much the end of privacy as another expression of marketing's desire to appropriate value from consumers without antagonizing them. The surveillance infrastructure is after all rather passive and the process of marketing based on Big Data not always very obvious or intrusive. However, Big Data desires to not only know reality but shape it. It is this aspect of Big Data marketing that makes it biopolitical and therefore so much more problematic than the analytical registers of privacy and surveillance suggest.

On this point, Zuboff's analysis of surveillance capitalism is instructive because Zuboff sees in the continuous experimental marketing interventions the potential for what she calls reality mining (see also Zwick and Denegri-Knott, 2009). The idea behind reality mining is that with experimentation researchers, businesses and what she somewhat vaguely calls the technological infrastructure can capture what people do at all times but also alter behavior, then capture again, then alter again and recaptured and so on. What 
is real and what is the outcome of real-time techno-cybernetic manipulation becomes indistinguishable (see also Elmer, 2004). It is through this recursive process that marketing aims to constitute not merely consumer subjects and identities but entire modes of being, or as Lazzarato (2004) puts it, entire worlds of capital-life.

\section{Digital possessions and consumer enclosure}

Marketing technologies of enclosure have morphed into lock in systems that both valorise and operate through consumers' psychic and financial investment in transforming digital objects into personally meaningful possessions. Within these digital enclosures, consumers own attempts to incorporate homogenous digital commodities into the domain of private possession end up facilitating their own entrapment (Molesworth, Watkins and Denegri-Knott, 2016). This enclosure also has the potential to amputate consumers from their digital possessions in ways that reduce a digital object's social utility and capacity to help develop and express personal identity. This mutation in technologies of enclosure not only diminishes the public domain as already noted (see Benkler, 2000; Lessig 1999) but also undermines the liberal ideals legitimising enclosing technologies themselves (see Denegri-Knott and Tadajewski 2010; Denegri-Knott and Tadajewski, 2016). Both classical and neo-libertarianism promote the idea that private goods are closely linked to our individuality in that the sense of control and privacy afforded by them allow us to develop and embody our personality as acts of self-actualization and will (Hegel 1821 in Gauss, 1994; Demsetz, 1967; Munzer 1990, Snare, 1972). It follows that it is only fair that those who invest themselves in transforming an object should have ownership rights over it (Demsetz, 1967; Locke 1988 [1689]; Munzer 1990; Snare, 1972). However, the right to full private property central to the neolibertarian project legitimating high tech companies’ rights to benefit from their investments in the digital economies is denied to consumers. Full property rights are often cited as paramount in conferring objects with an important role in helping people develop a sense of self and establishing and strengthening alliances between them. Hence technologies of enclosure fence in both public and private domains.

As a project of enclosure, these technologies operate by erecting proprietary walls around what consumers deem as their digital possessions. In doing so, they erode rights safeguarded by private ownership. Outright, total ownership, understood as 'exclusive rights of use and exploitation, to possess, manage, receive income from, power to transfer, exclude and abandon' (Snare 1972), it is claimed, is redundant within the context of digital consumption. Digital objects are complex entities that generally include code, software, hardware, Internet infrastructures and end user license agreements (EULAs) in 
order to be enacted and experienced as targets of consumption activity (Molesworth and Watkins, 2014; Watkins et al., 2016). Digital objects, like our e-books, playlists, social media posts, our Instagram pictures and video game purchases and prizes, in their material lightness are celebrated as both needs satisfying and liberating. Provided they are readily accessible they are likely candidates for communal sharing, (Belk 2013a, 2013b; Bardhi and Eckhardt, 2012; Bardhi et al., 2012), short term access, and good exemplars of liquid possessions- malleable and vaporous enough to fulfil consumers' functional and situational needs to suit shifting identity projects (Bardhi et al. 2012) without the obligations and responsibilities associated with ownership (Bardhi et al. 2012; Rifkin, 2000). As Rifkin (2000) notes, in a digitised, hyper speed network economy, ownership of physical capital 'becomes increasingly marginal' and access, primary source of value for both access providers and their users. Ownership again, is seen by Rifkin (2002) as too cumbersome and slow to keep up with the speed of delivery offered by Internet enabled platforms; instead of being burdened by ownership it pays to 'be always connected to a steady stream of just in time experiences.'

For these just in time experiences 'to pay' consumers need to 'pay' to access their digital objects. Digital objects are in effect rented rather than fully owned, because they require continuous investment of time, money and other resources in order to be accessed. Even pay-per-download digital objects once saved onto a password-protected account, like iTunes or Amazon's Kindle, become entangled with a firm's proprietary system limiting consumers' ability to transfer accumulated objects to a friend or family member (Denegri-Knott, 2015; Watkins et al., 2016). There are even lingering attachments between firms and consumers in situations where payment is not required. For example, though there is no direct monetary exchange between consumers and Facebook, Wordpress or YouTube, possession can be interrupted; digital objects may become lost or corrupted at any time. And here lies the paradox. Access is marketed as providing exactly what it denies: access. Note for example how subscription based services like Spotify are marketed on the premise that there are 'No More Limits' (Spotify News, 2014), or Amazonkindle’s ‘Bought Once, Read Everywhere’ (Wired, 2011) promise. Areas of access themselves are branded as 'my areas'; the music you curate with Spotify as a freemium customer is accessed in a menu entitled 'your music'. Bloggers and vlogers have 'their areas', 'their posts', 'their content'. The language of enclosure is nurturing and reassuring. It is the language of freedom and empowerment. It invites consumers to engage with digital objects as if they were theirs.

Reference to Igor Kopytoff's (1986) influential work on commodity biographies offers a useful entry point to see how digital possessions can operate as technologies of enclosure. Kopytoff's premise is that commodities are defined quantitatively and in relation to other commodities. Their tendency for 
proliferation is spearheaded by a commoditizing impulse, limited only by what 'the exchange technology permits' (Kopytoff, 1986, p. 87). On the other hand, singular possessions are defined qualitatively in terms to their relationship to cultural categories and personal histories. In that way, they are driven and defined by cultural and individual requirements to classify, discern and sacralise. In Kopytoff's proposed continuum between sacred, singularised objects and homogenised commodities, moving commodities from their market sphere into the domain of personal possession requires self-investment (Belk et al. 1989; McCracken 1986; Richins, 1994; Wallendorf and Arnould 1988). This includes work on meanings that attach an object to another person, a time or place (Csíkszentmihályi and Rochberg-Halton, 1981) or work on customizing, cleaning, repairing, displaying to create and maintain the preferential status of a meaningful or sacred possession (Belk et al., 1989).

Digital objects however cannot be transitioned so easily. Like their material equivalents, digital possessions that are experienced as meaningful are so because they have become focal points of psychological attention and investment over time (Denegri-Knott et al. 2012). Consider the time spent curating the perfect Spotify playlist or in winning trophies accumulated in game play. These digital objects have been in effect, to borrow from Csíkszentmihályi and Rochberg-Halton (1981), cultivated with focused attention and thus becoming meaningful possessions. Focused attention is expended in harnessing objects to help achieve a goal-for instance harvesting a character in a video game to help complete missions or in storing them to help protect their sacred status (Belk et al., 1989; Csíkszentmihályi and Rochberg-Halton 1981; Fournier, 1998; McCracken 1986; Richins, 1994). This investment produces relationships of attachment, where objects are not defined by their exchangeability to other things only, but rather by their qualitative relationship to personal histories (Belk, 1988) and cultural categories (Kopytoff, 1986).

Yet, in the case of digital objects, they are never too far from their market origins. In fact digital objects come to inhabit multiple positions, both as objects of personal significance and assets for the firms that help create and host them. In this way they are quasi possessions (see Denegri-Knott, 2015) or commodity-possession hybrids. This hybridity is well illustrated in Google's music streaming service, Google Play Music, with the service pitched as a combination of 'your collection and our catalogue' (The Guardian, 2016). As hybrids, singularising processes are equally commoditising, inasmuch as they are supported by market exchange. Differently put, commodity-possession hybrids are defined by singularising action that does not severe links to the market, because that action often enrols firm resources to cultivate their possession and because the hosting firm arbitrates access. Thus the more a consumer invests in crafting the perfect playlist on Spotify, the more reluctant she will be do abandon the 
service. The same applies to social media. Thus, processes of singularisation that are meant to strip objects from their commodity status are more market entangling, than severing (see Molesworth et al. 2016).

This creates an unusual situation, where possession becomes precarious and unstable. Consumers, having formed attachments to their digital objects continue to be entangled in on-going commercial relationships in ways that reconfigure supposedly inalienable possessions into technologies of enclosure that also happen valorise consumers' investments. If a consumer wants continued access to a favourite playlist or digital object, they will have to either continue to pay or at the very least engage with the hosting firm. In doing this, they help accrue profits for companies hosting their digital possessions. For example, users of social media make significant contributions in enhancing the social utility of the networking sites they use, and therefore also their exchange value. The benefits for Facebook, and MMORGs are obvious: consumers are locked into using platforms that host their meaningful digital possessions, and hosting companies benefit financially through monetising strategies facilitating access, either directly or through the sale of advertising. Consumers may also be subject to further monetising attempts from companies seeking to profit from their attachment to their digital possessions. To illustrate, when Facebook decided to delete photographs synched from users' phones to Facebook to encourage the adoption of their new Moments App, it was consumers' attachment to their accumulated photographs that catapulted the app into the top 100 free Android and iOS apps in the UK, and made it the third most popular free app on iOS (The Guardian, 2016).

Possessions as technologies of enclosure also diminish an object's social utility in ways that reduce consumers' freedom to control their own possessions. . Objects that are gifted, lent, shared and bequeathed fulfil important social functions- they can help establish and strengthen bonds of affiliation and reciprocity between people (Douglas and Isherwood, 1970; McCracken, 1986). Because full ownership of rights can be denied by EULAs, movement of digital objects may be unlikely. Take for instance limitations on gifting, re-selling and bequeathing imposed on many digital objects, and compare them to the rich biographies of fully owned material consumption objects: Amazon applies its own DRM to Kindle eBooks, meaning they cannot be accessed via other devices, Apple uses its FairPlay DRM to files that are purchased from the iBookstore limiting opportunities to share and lend. World of Warcraft's terms as conditions prohibits the selling, or trading of gifting of an account (Blizzard, 2016); iTunes collections cannot be lent, shared or bequeathed. There are no legal second hand markets for digital goods. In this way digital objects may be described as ‘terminal commodities’ (Appadurai, 1986). 
Similarly without the sanction of legal ownership, possession is fragile.

Only full ownership guarantees exclusive and future use over a possession, and thus the lack of this guarantee, limits our sense of freedom and independence. As Rudmin (1998) argues, failure to guarantee future use produces an unstable, precarious possession. Without the guarantees that total legal ownership provides, digital possession is precarious because it is prone to be disrupted or terminated at any time. Such disruptions threaten the very fabric of possession as an anchor for the development of the self and social linking, in that its objectual characteristics are no longer permanence and stability (Molesworth et al. 2016). This also undermines the classical and digital libertarian defence for the need for private ownership to nurture and safeguard our sense of independence and freedom. Instead, marketing systems of enclosure that operate through precarious possession as we have shown, supplant independence and freedom, with ever growing dependence and diminution of personal autonomy. Consumers in such systems of enclosure are best described as renters, in that, thinking alongside de Certeau (1984, p. 33), they only have transient rights to operate resources furnished by capitalism without real ownership. This creates a relationship of unbalanced dependency. The ultimate owners and arbitrators are the technologies of enclosure themselves- the firms providing access and hosting digital objects, who collectively produce, returning to de Certeau (1984, p. 40), a 'system too vast to be able to fix them [renters] in one place, too constraining for them [renters] ever to be able to escape'. So here, while opportunities and mechanisms to access and possess digital objects are vast, they also pin down renters to relationships of dependency that are not easily extricated. Consumers as renters cannot escape because having invested their psychological and financial resources in singularising digital objects into meaningful possessions, the costs of leaving are too high. Renting becomes a means of enclosure, because it is a precarious way of life, defined by uncertainty, dependency and reduced freedom. The idea that everything can be had, but not owned, is disingenuous in that nothing is ever had, only temporary access.

\section{Conclusion}

Marketing technologies - and more broadly marketing as technology - pursue the enclosure of the consumer subject (with Lazzarato, via the production of capital-worlds where specific consumer subjectivities are made possible) and of the commons (via the innovation of capitalist commons [see Zwick and Bradshaw, 2016] that permit the production and exploitation of collective productivity). What makes this marketing project so insidious is that at the same time that marketing (as) technology attempts to enclose its aspiration appears to be democratic: democratising access to good and services via digital 
possessions and sharing, democratising innovation and communication via brand communities and democratising information via Google and Big Data. The democratising discourse functions here ideologically because it allows marketers to resolve a key contradiction of marketing specific to participatory media: how to continue to control consumers in the age of democratisation, empowerment and participation.

Today, even digital possessions are becoming technologies of enclosure. Via the notion of entanglement and renting, we suggest that the digital never provides real ownership and the sort of freedom authentic possession can provide from power. Rather, digital possessions are always precarious and unstable. The possession remains meaningful only for as long as the "owner" of the possession also is its "user". Therefore, ever more entanglement with the object does not create possession and ownership but merely the right to its continuous use. In the age of biopolitical marketing, it is the job of marketers to ensure that this distinction disappears.

Is the insidious assimilation of revolutionary concepts - participation, empowerment, autonomy, democratic determination - not the perfect expression of the cultural logic of capitalism? Instead of pushing the consumer to accept a brand's version of the world, which can only lead to resistance and rejection of the message as the message of capital, the brand provides the context for what is then celebrated as the moment of "consumer empowerment”, when the consumer decides for herself that she really wants the brand and wanted it all along. But we should be very clear that this project of so-called consumer empowerment and consumer sovereignty gets consumers to the same place they were always already going to be. Therefore, in the age of biopolitical marketing, analyses of consumer empowerment fail unless they realize the concept’s ideological function in marketing practice.

Unlike the corporate persuaders of the 20th century, digital and social media marketers no longer aspire to command consumers to consume. These new marketers wish to unify marketing, community, conversation and the general work of making a life for oneself. There is no more separation between what the marketer wants and what the consumer wants. This is the credo of biopolitical marketing: in a world of total enclosure of consumers and the commons, marketers and consumers become one. Marketers want what consumers want and vice versa. Everyone is in this together, not on two different sides of an anachronistic struggle but participating on the same side in the making of worlds. The contradictions brought about by the increasing interaction of marketing and technology abound and any comprehensive 
analysis of marketing technologies in communicative capitalism has to take these contradictions into account.

After all, this symbiosis of marketer and consumer can never really hold. The consumer will always be the 'other' of marketing and the job of marketing can best be described as a process of constant and incessant identification and appropriation of a noncommodified 'other'. This fundamental tension will not go away but the technologies of identification and appropriation are constantly changing. In the era of what Zuboff (2015) calls Surveillance Capitalism, networked commercial reconnaissance has become a totalizing reality. To put it in the language of biopolitical marketing, surveillance capitalism is the latest stage in a continuous dialectic of marketing forever forced to oscillate between a relentless need for more and better "othering" and a desire to co-create worlds and "become one" with the other. We suggest that technology-enabled marketing techniques and tools therefore will always be measured against their ability to accomplish these two seemingly opposed tasks. We might be imprisoned but it will feel good.

\section{Bibliography}

Appadurai, A. (1986). Introduction: commodities and the politics of value. In A. Appadurai (Ed.), The Social Life of Things: Commodities in Cultural Perspective, pp. 3-63. Cambridge: Cambridge University Press.

Arvidsson, A. (2005). Brands: A critical perspective. Journal of Consumer Culture, 5(2), pp. 235-258.

Bardhi, F. and Eckhardt, G.M. (2012). Access-based consumption: The case of car sharing. Journal of Consumer Research, 39(4), pp. 881-898.

Bardhi, F., Eckhardt, G.M., and Arnould, E. (2012). Liquid relationship to possessions. Journal of Consumer Research, 39(3), pp. 510-529.

Belk, R.W. (2013a). Extended self in a digital world. Journal of Consumer Research, 40(3), pp. 477-500.

Belk, R.W. (2013b). You are what you can access: Sharing and collaborative consumption online. Journal of Business Research, 67(8), pp.1595-1600.

Belk, R.W., Wallendorf, M. and Sherry Jr., J.F. (1989). The sacred and the profane in consumer behavior: Theodicy on the Odyssey. The Journal of Consumer Research,16(1), pp. 1-38.

Benkler, Y. (2000). From consumers to users: Shifting the deeper structures of regulation toward sustainable commons and user access, Federal Communications Law Journal, 52(3), pp. 561-579. 
Cvijanovic, V., Vercellone, C., and Fumagalli, A. (2010). Cognitive Capitalism and its Reflections in South Eastern Europe. Frankfurt am Main: Peter Lang.

Czikszentmihalyi, M. and Rochberg-Halton, E. (1981). The Meaning of Things: Domestic Symbols and the Self. Cambridge, MA: Cambridge University Press.

De Certeau, M. (1988). The Practice of Everyday Life. Los Angeles, CA: University of California Press.

Dean, J. (2005). Communicative Capitalism: Circulation and the foreclosure of politics, Cultural Politics, 1 (1), pp. 51-74.

Demsetz, H. (1967). Toward a theory of property rights. The American Economic Review, 2, pp. 347-59.

Denegri-Knott, J., Watkins, R. and Wood, J. (2012). Transforming digital virtual goods into meaningful possessions. In M. Molesworth and J. Denegri-Knott (Eds.). Digital Virtual Consumption, pp. 76-91.

Oxford: Routledge.

Denegri-Knott, J. (2015). MP3. Consumption Markets and Culture, 18 (5), pp.397-401

Denegri-Knott, J. and Tadajewski, M. (2010). The emergence of MP3 technology. Journal of Historical Research in Marketing, 2, pp.397-425.

Denegri-Knott, J. and Tadajewski, M. (2016) 'Sanctioning Value: The Legal System, Hyper Power and the Legitimation of Market Systems, and the MP3, Marketing Theory, pp. 1-22.

Douglas, M. and Isherwood, B. (1979). The World of Goods, USA: Routledge.

Dyer-Whiteford, N. (2009). The Circulation of the Common. available at http://www.globalproject.info/it/in_movimento/Nick-Dyer-Witheford-the-Circulation-of-theCommon/4797, accessed 02/02, 2012

Elmer, G. (2004). Profiling Machines: Mapping the Personal Information Economy. Cambridge, MA: MIT Press.

Fuchs, C. (2010). Labor in Informational Capitalism and on the Internet. The Information Society, 26(3), 179-196. doi:10.1080/01972241003712215.

Fuchs, C. (2012). Dallas Smythe Today- The audience Commodity, the Digital Labour Debate, Marxist Political Economy and Critical Theory. Porolegomena to a Digital Labour Theory of Value. TripleC, 10(2), 692-740.

Gaus, G. (2012). Property and Ownership. In Estlund D. (Ed.) Oxford Handbook of Political Philosophy, pp. 93-112. Oxford: Oxford University Press.

Godin, S. (1999). Permission Marketing: Turning Strangers Into Friends, and Friends Into Customers. New York: Simon \& Schuster. 
Hardt, M., and Negri, A. (2009). Commonwealth. Cambridge, MA.: Belknap Press of Harvard University Press.

Juergenson, N. (2010). The de-McDonaldization of the Internet. In G. Ritzer (Ed.), McDonaldization: The Reader (pp. 159-170). Thousand Oaks, CA: Pine Forge Press.

Kopytoff, I. (1986). The cultural biography of things, commoditization as a Process. In A. Appadurai (Ed.) The Social Life of Things Commodities in a Cultural Perspective (64-94). Cambridge: Cambridge University Press.

Lanier, J. (2013). Who Owns the Future? (First Simon \& Schuster hardcover edition. ed.). New York, NY: Simon \& Schuster.

Lazzarato, M. (2004). From capital-labour to capital-life. Ephemera: Theory \& Politics in Organization, 4(3), pp.187-208.

Lessig, L. (1999). Code and Other Laws of Cyberspace, New York, NY: Basic Books.

Lury, C. (2004). Brands: The Logos of the Global Economy. London: Routledge.

McCracken, G. (1986) Culture and consumption: A theoretical account of the structure and movement of the cultural meaning of consumer goods, Journal of Consumer Research, 13, (June), pp. 71-84.

Molesworth, M and Watkins, R. (2014). Adult videogame consumption as individualised, episodic progress. Journal of Consumer Culture, 16 (2),pp. 510-530.

Molesworth, M., Watkins, R. and Denegri-Knott, J. (2016). Possession work on hosted digital consumption objects as consumer ensnarement. Journal of the Association for Consumer Research, 1(2), pp. 246-261.

Munzer, S. (1990). A Theory of Property, Cambridge: Cambridge University Press.

Packard, V. O. (1957). The Hidden Persuaders. New York: Pocket Books.

Richins, M. (1994). Valuing things, the public and private meanings of possessions. Journal of Consumer Research, 21 (3), pp. 504-521.

Rifkin, J. (2000). The Age of access: The New Culture of Hypercapitalism Where all of Life is a Paid for Experience. New York: Penguin.

Rifkin, J. (2002). The age of access, the new politics of culture vs. commerce, Ars Electronica. Available at: http://90.146.8.18/en/archives/festival_archive/festival_catalogs/festival_artikel.asp?iProjectID=11765 [accessed Jan 4 2015).

Snare, F. (1972). The concept of property. American Philosophical Quarterly, 9 (2), pp. 200-06. 
Solis, B. (2010). Engage! the Complete Guide for Brands and Businesses to Build, Cultivate, and Measure Success in the New Web. Hoboken, N.J.: John Wiley.

Spotify News (2014). No more Limits, Available at: https://news.spotify.com/uk/2014/01/15/no-moretime-limits-on-spotify-freeyourmusic/ [accessed Jan 4 2015).

The Guardian (2016). Which is the best music streaming service? Available at: https://www.theguardian.com/technology/2016/feb/16/which-is-the-best-music-streaming-service-spotifyapple-music [accessed June 4 2016).

Wallendorf, M. and Arnould, E. (1988). 'My favorite things': A cross-cultural inquiry into object attachment, possessiveness, and social linkage. Journal of Consumer Research, 14 (March), pp.531-547.

Watkins, R.D., Denegri-Knott, J. and Molesworth, M. (2016). The relationship between ownership and possession: observations from the context of digital virtual goods. Journal of Marketing Management, 32 (1-2), pp.44-70

Zuboff, S. (2015). Big Other: Surveillance Capitalism and the prospects of an information civilization. Jounal of Information Technology, 30, pp.75-89.

Zwick, D., and Bradshaw, A. (2016). Biopolitical marketing and social media brand communities. Theory, Culture \& Society, 33(5), pp. 91-115.

Zwick, D., and Denegri-Knott, J. (2009). Manufacturing customers: The database as new means of production. Journal of Consumer Culture, 9(2), pp. 221-247. 